\title{
Sludge minimization in municipal wastewater treatment by polyhydroxyalkanoate (PHA) production
}

\author{
Francesco Valentino • Fernando Morgan-Sagastume - Serena Fraraccio • \\ Giovanna Corsi • Giulio Zanaroli • Alan Werker • Mauro Majone
}

Received: 19 March 2014 / Accepted: 27 June 2014

(C) Springer-Verlag Berlin Heidelberg 2014

\begin{abstract}
An innovative approach has been recently proposed in order to link polyhydroxyalkanoates (PHA) production with sludge minimization in municipal wastewater treatment, where (1) a sequencing batch reactor (SBR) is used for the simultaneous municipal wastewater treatment and the selection/enrichment of biomass with storage ability and (2) the acidogenic fermentation of the primary sludge is used to produce a stream rich in volatile fatty acids (VFAs) as the carbon source for the following PHA accumulation stage. The reliability of the proposed process has been evaluated at lab scale by using substrate synthetic mixtures for both stages, simulating a low-strength municipal wastewater and the effluent from primary sludge fermentation, respectively. Six SBR runs were performed under the same operating conditions, each time starting from a new activated sludge inoculum. In every SBR run, despite the low VFA content $(10 \%$ chemical oxygen demand, COD basis) of the substrate synthetic mixture, a stable feast-famine regime was established, ensuring the necessary selection/enrichment of the sludge and soluble
\end{abstract}

Responsible editor: Angeles Blanco

F. Valentino $(\bowtie) \cdot$ G. Corsi $\cdot$ M. Majone

Department of Chemistry, "Sapienza" University of Rome,

P.le Aldo Moro 5, 00185 Rome, RM, Italy

e-mail: francesco.valentino@uniroma1.it

F. Morgan-Sagastume $\cdot$ A. Werker

AnoxKaldnes AB, Klosterängsvägen 11A, 22647 Lund, Sweden

S. Fraraccio $\cdot$ G. Zanaroli

Department of Civil, Chemical, Environmental and Materials

Engineering (DICAM), University of Bologna,

Via Umberto Terracini 28, 40131 Bologna, BO, Italy

S. Fraraccio • G. Zanaroli

Interuniversity Consortium "Chemistry for the Environment"

(INCA), Via delle Industrie 21/8,

30175 Venezia-Marghera, VE, Italy
COD removal to $89 \%$. A good process reproducibility was observed, as also confirmed by denaturing gradient gel electrophoresis (DGGE) analysis of the microbial community, which showed that a high similarity after SBR steady-state had been reached. The main variation factors of the storage properties among different runs were uncontrolled changes of settling properties which in turn caused variations of both sludge retention time and specific organic loading rate. In the following accumulation batch tests, the selected/enriched consortium was able to accumulate PHA with good rate (63 mg COD ${ }_{\text {PHA }}$ g $\left.\mathrm{COD}_{\mathrm{Xa}}{ }^{-1} \mathrm{~h}^{-1}\right)$ and yield $\left(0.23 \mathrm{COD}_{\mathrm{PHA}}\right.$ $\mathrm{COD}_{\Delta \mathrm{S}^{-1}}$ ) in spite that the feeding solution was different from the acclimation one. Even though the PHA production performance still requires optimization, the proposed process has a good potential especially if coupled to minimization of both primary sludge (by its use as the VFA source for the PHA accumulation, via previous fermentation) and excess secondary sludge (by its use as the biomass source for the PHA accumulation).

Keywords Mixed microbial culture $\cdot$ Polyhydroxyalkanoate Sequencing batch reactor

\section{Introduction}

In the last decades, polyhydroxyalkanoates (PHA) have attracted industrial and market interest not only because their thermoplastic properties are coupled to good biodegradability, but also because they can be synthesized from renewable carbon resources, such as industrial and/or agricultural wastes. Different microorganisms like Alcaligenes latus, Azotobacter vinelandii, Ralstonia eutropha and several strains of recombinant Escherichia coli have been intensively investigated, being able to accumulate PHA up to $90 \%$ of cell dry weight (Wang and Lee 1997). 
However, full market exploitation of PHA is still limited by the high production cost or pure culture fermentation processes (Chanprateep 2010).

In order to reduce the cost of maintenance and growth of pure cultures (and avoiding the need for sterile conditions), mixed microbial culture (MMC) processes have been largely investigated (Dias et al. 2006; Reis et al. 2011). The effectiveness of MMC PHA production processes is strongly dependent on selection principles of operating conditions in an open bioreactor that impose a strong pressure in favour of microorganisms that are most able to store PHA. This objective is usually achieved by imposing feast-famine (FF) conditions, usually done by dynamic feeding of a sequencing batch reactor (SBR) (Majone et al. 1996; Dionisi et al. 2001; Serafim et al. 2004). Coupled with MMC systems, considerable attention has been given to the use of no-cost carbon sources, such as paper mill wastewater (Bengtsson et al. 2008), tomato cannery wastewater (Liu et al. 2008), olive oil mill effluent (Beccari et al. 2009), sugar cane molasses (Albuquerque et al. 2010), food waste (Reddy Venkateswar and Mohan Venkata 2012) and kraft mill wastewaters (Pozo et al. 2011). Most of these available feedstocks require a preliminary acidogenic fermentation stage to convert their organic content into volatile fatty acids (VFAs), the most suitable substrates for PHA production when using MMC processes. Moreover, the MMC selection and PHA accumulation stages are usually performed in separate stages, because optimal conditions are different for each stage (Reis et al. 2011). Hence, MMC PHA processes have been commonly investigated in a three-stage arrangement: (1) the acidogenic fermentation stage, (2) the culture selection stage (SBR) and (3) the PHA accumulation stage. This strategy has allowed a good performance in terms of PHA productivity (up to $6.0 \mathrm{~g} \mathrm{PHA} \mathrm{L}^{-1}$ day $^{-1}$; Dionisi et al. 2006) and final PHA content (65\% g PHA g total suspended solid, TSS $^{-1}$, Serafim et al. 2004).

In recent years, there has been increasing interest in producing PHA by using as the carbon source the VFA-rich effluent from acidogenic fermentation of excess sludge from activated sludge wastewater treatment (Jia et al. 2013; Chua et al. 2003; Morgan-Sagastume et al. 2010). Recently, a novel approach has been proposed to link PHA production with municipal wastewater treatment and sludge minimization as well (Morgan-Sagastume et al. 2014). The key feature of the proposed approach (Fig. 1) is that the VFA-rich effluent from primary sludge fermentation is driven to the PHA production stage only whereas the required MMC selection stage is performed by using the municipal wastewater in an ad hoc designed activated sludge process, which at the same time provides at least preliminary wastewater treatment (COD removal) but, potentially, also carbon and nitrogen treatment (Anterrieu et al. 2013). This strategy aims to increase the yield of PHA production on fed VFA, which is usually low (no more than $10-15 \%$ ) in the more conventional three-stage process due to the VFA consumption occurring during the biomass selection step where PHA is necessarily cycling between storage and consumption. As for sludge minimization, the proposed process could be advantageous in two ways: the primary sludge is strongly reduced by converting organic solids into VFA through acidogenic fermentation and the excess secondary sludge with enhanced PHA-storing capacity from the SBR is fully conveyed to the PHA accumulation step.

On the other hand, the possibility to effectively use a lowstrength, VFA-poor, municipal wastewater to select and produce a biomass with enough high storage capability has to be carefully evaluated in terms of its PHA production performance (i.e. PHA fraction in the biomass and daily PHA productivity). Preliminary experiments at pilot scale with a real municipal wastewater gave promising results: The selected biomass was characterized by good storage properties (PHA formation rate and yield) even though the final PHA content was rather lower than using more specialized MMC (Morgan-Sagastume et al. 2014).

This paper aims to confirm such a preliminary experience, by doing a more basic investigation of the process rationale, under controlled conditions. For this purpose, lab-scale experiments were performed by using an SBR that was fed with a complex mixture of different organic substrates, mimicking the soluble COD of municipal wastewater. Attention was given to evaluating process reliability and robustness, by performing six SBR runs repeatedly under the same operating conditions, even if a fresh inoculum was used for SBR start-up in each run. For each SBR run, the PHA accumulation capacity of the selected MMC was then evaluated by using batch accumulation tests, which were carried out with a synthetic mixture of acetic and propionic acid, used as a reference for mimicking the VFA-rich effluent from acidogenic fermentation of excess primary sludge. Moreover, microbial population dynamics of each selected MMC were also investigated.

\section{Materials and methods}

\section{SBR operation}

An SBR (working volume of $1 \mathrm{~L}$ ) was utilized for culturing the activated sludge under periodic feeding conditions. It was inoculated with activated sludge from the "Roma Nord" fullscale plant. Six runs were conducted under the same process conditions: organic loading rate (OLR) 3.08 g COD $\mathrm{L}^{-1}$ day $^{-1}$, hydraulic retention time (HRT) $2.14 \mathrm{~h}$, sludge retention time (SRT) 1.5 day, cycle length $1.5 \mathrm{~h}$, temperature $22.5^{\circ} \mathrm{C}$ (controlled by a thermostatic jacket) and $\mathrm{pH}$ 8.0. The SBR operated with 16 cycles per day (90 min each), including biomass discharge ( $0.5 \mathrm{~min}$, mixing) feeding ( $2.5 \mathrm{~min}$, aeration and mixing), reaction (59.5 min, aeration and mixing), 
Fig. 1 Schematic process flow diagram of municipal wastewater and sludge treatment in conjunction with PHA production under study in the project ROUTES. Laboratory-scale studies are conducted on the biomass and polymer production processes ("Sapienza" University of Rome, AnoxKaldnes)

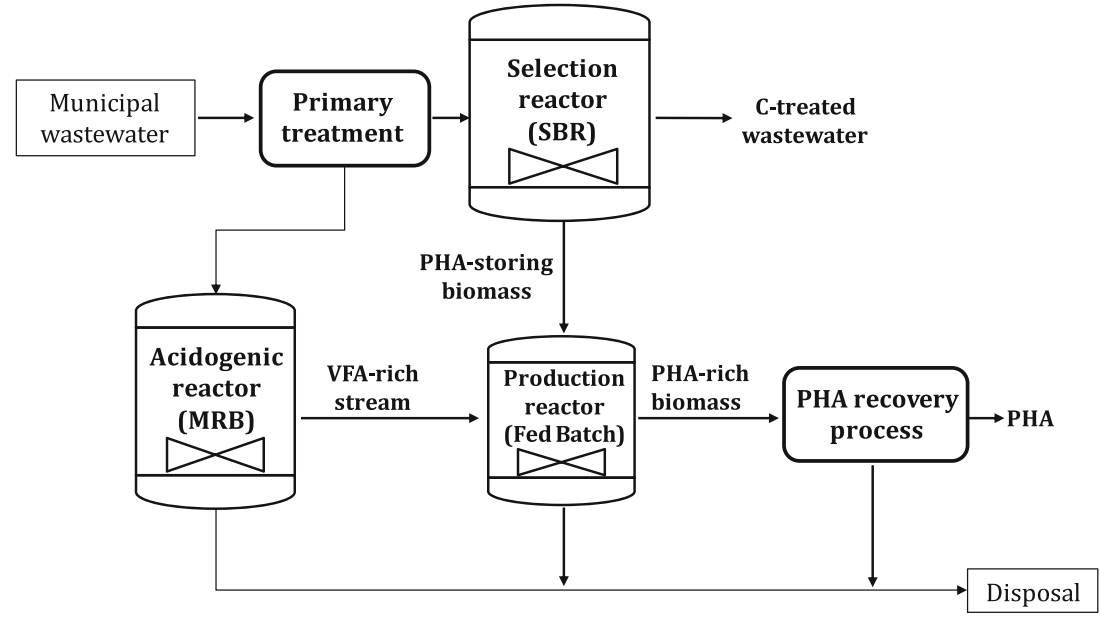

settling (20 min) and effluent discharge (7.5 min) under quiescent conditions. Excess sludge targeting the SRT was wasted eight times per day, on average. The reactor was aerated by means of membrane compressors and stirred by a mechanical impeller at $250 \mathrm{rpm}$. Each run was operated for a period ranging from 28 to 84 days. The SBR was fed with a synthetic mixture of soluble organic substrates and inorganic compounds: acetic acid, yeast extract, glucose, starch and peptone being at 11, 13, 27, 25 and $24 \%$ in terms of COD fraction, respectively, and $\mathrm{NH}_{4} \mathrm{Cl}\left(35 \mathrm{mg} \mathrm{N}-\mathrm{NH}_{4}{ }^{+} \mathrm{L}^{-1}\right)$ and $\mathrm{KH}_{2} \mathrm{PO}_{4}\left(3 \mathrm{mg} \mathrm{P}-\mathrm{PO}_{4}{ }^{3-} \mathrm{L}^{-1}\right)$. This substrate synthetic mixture had a total COD content equal to $275 \mathrm{mg} \mathrm{L}^{-1}$; its composition and concentration were chosen to simulate the soluble fraction of a typical municipal wastewater (MWW) after primary settling (Andalib et al. 2010; Antoniadis et al. 2010; Carucci et al. 2001; Chen et al. 2006; Jin et al. 2012; Kargi and Uygur 2003; Kositzi et al. 2004; Yoo et al. 2012).

During each SBR cycle, the dissolved oxygen (DO) was continuously monitored in order to identify the period in which the readily biodegradable COD (RBCOD) substrates were exhausted, as indicated by the sudden slope change of the $\mathrm{O}_{2}$ concentration time profile. The period included between the start of the feeding and the slope change was referred to the feast phase length. In the rest of the reaction phase, the so-called famine phase, the slowly biodegradable COD (SBCOD) was consumed. In each SBR run, it was considered that a pseudosteady state was obtained when the feast phase length remained approximately constant (within $5 \%$ deviation from average values) for at least five consecutive days.

The SBR performance during the steady-state was monitored by the measurement of biomass concentration, as volatile suspended solid (VSS, sample taken at the end of the feast phase) and PHA (sample taken at the end of the feast phase and at the end of the cycle). In addition, the suspended solid content (TSS and VSS) and the COD were estimated in the effluent in order to control the settling property of the biomass and the COD removal efficiency of the system.
Batch tests

Aerobic fed-batch tests were carried out in a 0.5-L working volume reactor at the same temperature and $\mathrm{pH}$ as those of SBR. They were performed in order to investigate the PHA accumulation capacity of the biomass, taken from SBR, once the operating steady-state was reached. The tests were performed in the presence of excess nitrogen, i.e. with no additional growth limitation but the one caused by the previous feast-famine regime. Although higher storage performance is usually obtained under also nitrogen limitation (Serafim et al. 2004; Dionisi et al. 2006), this condition is not representative of the composition of fermented wastes, or more specifically, fermented sludge, which are usually rich in nitrogen and nutrients in general (Yuan et al. 2010; Wu et al. 2009). The biomass withdrawn from the SBR was diluted to a lower concentration $\left(0.5 \mathrm{~g} \mathrm{VSS} \mathrm{L}^{-1}\right)$ with $0.2 \mathrm{~L}$ of mineral medium (Valentino et al. 2013) and tap water. $\mathrm{NH}_{4} \mathrm{Cl}$ was added at the beginning of the tests in order to reach $100 \mathrm{mg} \mathrm{N}-\mathrm{NH}_{4}{ }^{+} \mathrm{L}^{-1}$ as initial concentration.

Preliminary short-term batch tests $(6 \mathrm{~h})$ were carried out with synthetic substrates (acetic and propionic acid $85-15 \%$ on a COD basis), in order to mimic a possible (simplified) composition of VFA-rich streams coming from the acidogenic fermentation of primary sludge. The concentrated solution of VFA was spiked at the beginning of the accumulation $(1 \mathrm{~mL})$ in order to obtain a VFA/VSS ratio around 2.0 on a COD basis. This ratio ensured the presence of substrate for all the test length (no famine phase allowed), preventing polymer consumption. During SBR runs III-IV-V-VI, the accumulation tests were extended until $24 \mathrm{~h}$. These long-term batch tests were carried out with the same substrate and initial $\mathrm{NH}_{4} \mathrm{Cl}$ additions and with a further substrate spike $8 \mathrm{~h}$ after the beginning of the accumulation, in order to have substrate availability during the whole test. The evolution of the storage/growth response was evaluated for such a long time, in order to check if the PHA saturation level was eventually reached. 
In all of the tests, the sludge in the reactor was sampled at regular intervals for analytical determination of the carbon substrates, storage compounds and ammonium. Before and during each test, the reactor was maintained under air bubbling (at oxygen concentrations around $8.0 \mathrm{mg} \mathrm{L}^{-1}$ ). In order to measure the oxygen uptake rate (OUR), the aeration was interrupted at intervals and the DO decrease was measured as a function of time; however, the DO concentration never decreased below $2.0 \mathrm{mg} \mathrm{L}^{-1}$.

For each fed-batch test (short- or long-term), at least two replicates were carried out, with biomass acclimated in each SBR run.

\section{Analytical methods}

The VFA (acetate and propionate) were measured after filtration on $0.45-\mu \mathrm{m}$ porosity filter, by gas chromatography (stationary phase Carbowax $20 \mathrm{~mol} \mathrm{~L}^{-1}, 4 \%$ on CarboPack B-DA; DaniMaster GC-flame ionization detector, FID). The ammonium ions, carbohydrates and glucose were also measured on filtered samples. The Nessler spectrophotometric method at 420-nm wavelength (Shimadzu UV-1800 Spectrophotometer) was used for ammonium measurements, through the absorbance detection of the final coloured complex. The total carbohydrates were detected with the phenol-sulfuric colorimetric method, by measuring the absorbance at 488-nm wavelength (Shimadzu UV1800 Spectrophotometer). The glucose was detected by using Sigma-Aldrich enzymatic kit assay (GAHK-20) by measuring the absorbance of the final product at 340-nm wavelength (Shimadzu UV-1800 Spectrophotometer).

For PHA determination, $5 \mathrm{~mL}$ of the mixed liquor sample was initially treated with $1-\mathrm{mL} \mathrm{NaClO}$ solution $(7 \%$ active $\mathrm{Cl}_{2}$ ) and stored at $-4{ }^{\circ} \mathrm{C}$ later analysis. The PHA granules were extracted, hydrolyzed and esterified to 3-hydroxyacyl methyl esters and finally determined by gas chromatography method (Braunegg et al. 1978). The relative abundance of 3hydroxybutyrate (HB) and 3-hydroxyvalerate (HV) monomers was quantified by using a commercial co-polymer as standard, poly(3-hydroxybutyric acid-co-3-hydroxyvaleric acid) (P[3-HB-co-3-HV]), Sigma-Aldrich), at $5 \% \mathrm{wt}$ HV content.

The active biomass $\left(X_{\mathrm{A}}\right)$, or non-polymer biomass, was calculated at the end of feast phase, from the difference between VSS and PHA: $X_{\mathrm{A}}=(\mathrm{VSS}-\mathrm{PHA}) \cdot 1.42$. This value was converted into $\mathrm{COD}$, according to a conversion factor of $1.42 \mathrm{mg}$ COD $\mathrm{mg}_{\mathrm{A}}^{-1}$. The latter conversion factor was obtained by considering the generic heterotrophic biomass formula $\mathrm{C}_{5} \mathrm{H}_{7} \mathrm{O}_{2} \mathrm{~N}$ (Gujer and Henze 1991). PHA mass was also converted in units of $\mathrm{COD}$ according to oxidation stoichiometry: $1.67 \mathrm{mg}$ COD mg 3-HB ${ }^{-1}$ monomer and $1.92 \mathrm{mg}$ COD mg 3$\mathrm{HV}^{-1}$ monomer. The PHA content of the biomass was calculated by dividing the measured PHA concentration by biomass concentrations (both expressed as $\mathrm{mg} \mathrm{L}^{-1}$ ).

\section{Calculations}

The relative fraction of RBCOD and SBCOD was evaluated from the $\mathrm{O}_{2}$ concentration profile in the cycles of SBR runs (see "Materials and methods" section), taking into account the total COD fed in each cycle. Specifically, the integral calculation of the $\mathrm{O}_{2}$ curve was split into two zones, discriminated by the time of RBCOD depletion. This calculation was made in each sampling cycle.

The specific RBCOD removal rate was calculated as the ratio of the RBCOD removed $\left(\Delta S_{\mathrm{RBCOD}}\right.$, calculated in each specific cycle) and the length of feast phase $(t)$, per unit of $X_{\mathrm{A}}$ : $\left(-\mathrm{q} S_{\mathrm{RBCOD}}\right)=\Delta S_{\mathrm{RBCOD}} /\left(t \cdot X_{\mathrm{A}}\right)$.

The amount of stored PHA ( $\triangle \mathrm{PHA})$ during an SBR cycle was calculated as the difference between PHA concentration in the mixed liquor at the end of feast phase (i.e. the RBCOD depletion time) and at the end of the previous famine phase. The specific PHA production rate was calculated as the ratio of stored PHA and the length of feast phase $(t)$, per unit of $X_{\mathrm{A}}$ : $\mathrm{q} P^{\text {feast }}=\Delta \mathrm{PHA} /\left(t \cdot X_{\mathrm{A}}\right)$.

The storage yield during the feast phase was determined as the ratio between the amount of stored PHA (as COD) and the amount of the RBCOD removed: $\mathrm{Y}_{\mathrm{P} / \mathrm{S}}{ }^{\text {feast }}=\Delta \mathrm{PHA} / \Delta S_{\mathrm{RBCOD}}$.

The observed yield $\left(Y_{\mathrm{OBS}}{ }^{\text {cycle }}\right)$ was determined based on the SBR mass balance. The considered parameters were as follows: the daily influent, effluent and biomass discharge flow rates (respectively $Q_{\mathrm{in}}, Q_{\mathrm{E}}, Q_{\mathrm{S}}, \mathrm{L}_{\text {day }}{ }^{-1}$ ) as the SBR streams and the influent COD, the effluent and discharge biomass concentrations (respectively $S_{\mathrm{in}}, \mathrm{VSS}_{\mathrm{E}}, \mathrm{VSS}_{\mathrm{S}}, \mathrm{mg}$ $\mathrm{COD} \mathrm{L}^{-1}$ ) relative to each streams. The effluent COD concentration $\left(S_{\mathrm{E}}, \mathrm{mg} \mathrm{COD} \mathrm{L}^{-1}\right)$ was also taken into account. As consequence:

$Y_{\mathrm{OBS}}^{\text {cycle }}=\left(\left(Q_{\mathrm{S}} \cdot \mathrm{VSS}_{\mathrm{S}}\right)+\left(\mathrm{Q}_{\mathrm{E}} \cdot \mathrm{VSS}_{\mathrm{E}}\right)\right) /\left(\left(\mathrm{Q}_{\text {in }} \cdot \mathrm{S}_{\text {in }}\right)-\left(\mathrm{Q}_{\mathrm{E}} \cdot \mathrm{S}_{\mathrm{E}}\right)\right)$

The polymer content in the biomass was calculated (in terms of COD) at RBCOD depletion as the ratio of PHA concentration and VSS concentration (i.e. the sum of active biomass and produced polymer):

$\% \mathrm{PHA}=\mathrm{PHA} / \mathrm{VSS}=\mathrm{PHA} /\left(X_{\mathrm{A}}+\mathrm{PHA}\right)$.

The COD removal efficiency was calculated as ratio between the soluble COD of the effluent and the soluble COD fed in each cycle. The specific OLR was calculated as the ratio between the OLR and the SBR VSS concentration at the end of feast, both expressed in terms of COD.

In the fed-batch tests, the specific rates $\left(\mathrm{qHB}^{\text {batch }}, \mathrm{qHV}^{\text {batch }}\right.$ and $\mathrm{q} P^{\text {batch }}$ for 3-HB, 3-HV and PHA storage, respectively; $-\mathrm{q} S_{\mathrm{Ac}}{ }^{\text {batch }},-\mathrm{q} S_{\mathrm{Pr}}{ }^{\text {batch }}$ and $-\mathrm{q} S_{\mathrm{VFA}}{ }^{\text {batch }}$ for acetic acid, propionic acid and VFA uptake, respectively) were calculated by linear regression of data versus time, for which case, only the initial period of $3.0 \mathrm{~h}$ maximum from the beginning of the tests at 
constant rate was considered. The volumetric rates were transformed into specific rates, using the $X_{\mathrm{A}}$ concentration at the end of the initial period. For this calculation, the new active biomass grown was evaluated from ammonium consumption, by considering the mean nitrogen content in the biomass (10\% as $\left.\mathrm{g} \mathrm{N} X_{\mathrm{A}}^{-1}\right)$. The final growth yield $\left(Y_{\mathrm{X} / \mathrm{S}}{ }^{\text {batch }}\right)$ was calculated as the ratio between the new $X_{\mathrm{A}}$ produced and the removed substrate both expressed in COD, at the end of the test: $Y_{\mathrm{X} / \mathrm{S}}{ }^{\text {batch }}=\Delta \mathrm{PHA} / \Delta \mathrm{S}$.

The final storage yield $\left(Y_{\mathrm{P} / \mathrm{S}}{ }^{\text {batch }}\right)$ was calculated as the ratio between the PHA produced and the removed substrate both expressed in COD, at the end of the test: $Y_{\mathrm{P} / \mathrm{S}}{ }^{\text {batch }}=\Delta X_{\mathrm{A}} / \Delta \mathrm{S}$.

The final polymer content in the biomass was calculated in terms of percentage as explained above.

\section{Molecular analysis of microbial communities}

PCR-denaturing gradient gel electrophoresis (DGGE) analysis of $16 \mathrm{~S}$ recombinant RNA (rRNA) genes was used to investigate changes of the bacterial community structure during SBR runs. Metagenomic DNA was extracted in duplicate with the UltraClean Soil DNA kit (MoBio Laboratories, Carlsbad, CA, USA) from approximately $250 \mathrm{mg}$ of sludge pellet. PCR amplification of the V3-V5 variable regions was performed with primers GC-357f and GC-907r as described previously (Zanaroli et al. 2010). Obtained amplicons were resolved with a DCode Universal Mutation Detection System (Bio-Rad, Milan, Italy) on a $7 \%(w / v)$ polyacrylamide gel (acrylamide-N,N'-methylenebisacrylamide, 37:1) containing a denaturing gradient from 40 (top) to $60 \%$ (bottom) denaturant (100\% denaturant $7 \mathrm{M}$ urea, $40 \% v / v$ formamide). The electrophoresis was run at $55 \mathrm{~V}$ for $16 \mathrm{~h}$ at $60{ }^{\circ} \mathrm{C}$. The gel was stained with $1 \times$ SYBR Green I (Sigma-Aldrich, Milan, Italy) for $30 \mathrm{~min}$ and its image digitally captured in UV transillumination with a Gel Doc apparatus (Bio-Rad, Milan, Italy). Similarities between DGGE profiles were calculated using the Dice coefficient with Quantity One 4.5.2 software (BioRad). DGGE patterns were then clustered using the unweighted pair-group arithmetic average (UPGAMA) clustering algorithm. Moving windows analysis was performed based on the DGGE profiles as described in Marzorati et al. (2008). The analysis provides the \%change value between consecutive sampling points and the rate of change parameter, which averages the rate of change between consecutive DGGE profiles of the same community over a fixed time interval. Usually, a time interval of approximately 1 week was considered, although shorter time intervals (1-3 days) were also taken into consideration during the start-up (first week) of the shorter SBR runs (Runs I, II and III).

To characterize the composition of selected microbial communities, metagenomic libraries of the 16S rRNA genes were constructed. 16S rRNA genes were PCR amplified from the metagenome with the primer pair $27 \mathrm{f} / 1525 \mathrm{r}$ as described in
Zanaroli et al. (2010). Amplicons were cloned in pCR ${ }^{\circledR} 4$ $\mathrm{TOPO}^{\circledR}$ cloning vector (Invitrogen, Paisley, UK) and the resulting plasmids inserted in chemically competent One Shot ${ }^{\circledR}$ TOP10 E. coli cells (Invitrogen, Paisley, UK) following the manufacturer's instructions. Transformed cells were plated on $\mathrm{LB}$ agar plates containing $100 \mu \mathrm{g} \mathrm{mL}^{-1}$ ampicillin and incubated overnight at $37^{\circ} \mathrm{C}$, and colonies were picked using a toothpick and grown overnight in liquid LB medium with $100 \mu \mathrm{g} \mathrm{mL}^{-1}$ ampicillin. Library screening was performed by DGGE analysis. Briefly, plasmids were extracted with a modified alkaline lysis miniprep protocol (Sambrook et al. 1989) and a portion of the inserts amplified with the primer pair GC$357 \mathrm{f}$ and $907 \mathrm{r}$ and resolved on a $7 \%(w / v)$ polyacrylamide gel containing a 40 to $60 \%$ denaturant gradient as described above. Amplicons obtained from the metagenome with the same primer pair were loaded on DGGE gels together with amplicons obtained from clones in order to assign each clone to a DGGE band of the community during the screening. Full inserts of clones giving a unique band in DGGE gels were PCR amplified with primers $27 \mathrm{f}$ and $1525 \mathrm{r}$ and amplicons purified with ExoSAP-IT ${ }^{\circledR}$ (Affymetrix, Santa Clara, CA) before being sequenced with primers $27 \mathrm{f}$ and 1525r (BMR Genomics, Padova, Italy). Sequences were aligned to the Ribosomal Database Project (RDP, release 10) sequence database and closest relatives retrieved with the SeqMatch tool.

\section{Results and discussions}

\section{SBR performance}

\section{Selection of biomass on the substrate synthetic mixture:} the typical SBR cycle

On average, the MMC needed almost 1 week of operation ( $4 / 5$ SRT) in order to achieve a stable response to the imposed process conditions, which was verified by the reproducibility of the oxygen profiles along the cycle (Fig. 2).

A sudden increase of the $\mathrm{O}_{2}$ concentration was observed a short time after the feeding was completed, which was considered to correspond to the depletion of most of the readily biodegradable COD (RBCOD) substrates. The RBCOD depletion time was also considered to correspond to the length of the "feast" phase, and in spite of that, the progressive slow increase of the $\mathrm{O}_{2}$ concentration in the "famine" phase suggests that the consumption of the residual SBCOD was still continuing (Fig. 2a). Based on the respective areas of the $\mathrm{O}_{2}$ concentration-time profiles, the RBCOD fraction accounted for the $35-40 \%$ of the total removed COD. Correspondingly, at the end of the feast phase, the acetic acid was totally consumed along with most of the glucose (Fig. 2b); the remaining SBCOD was mostly removed during the famine 

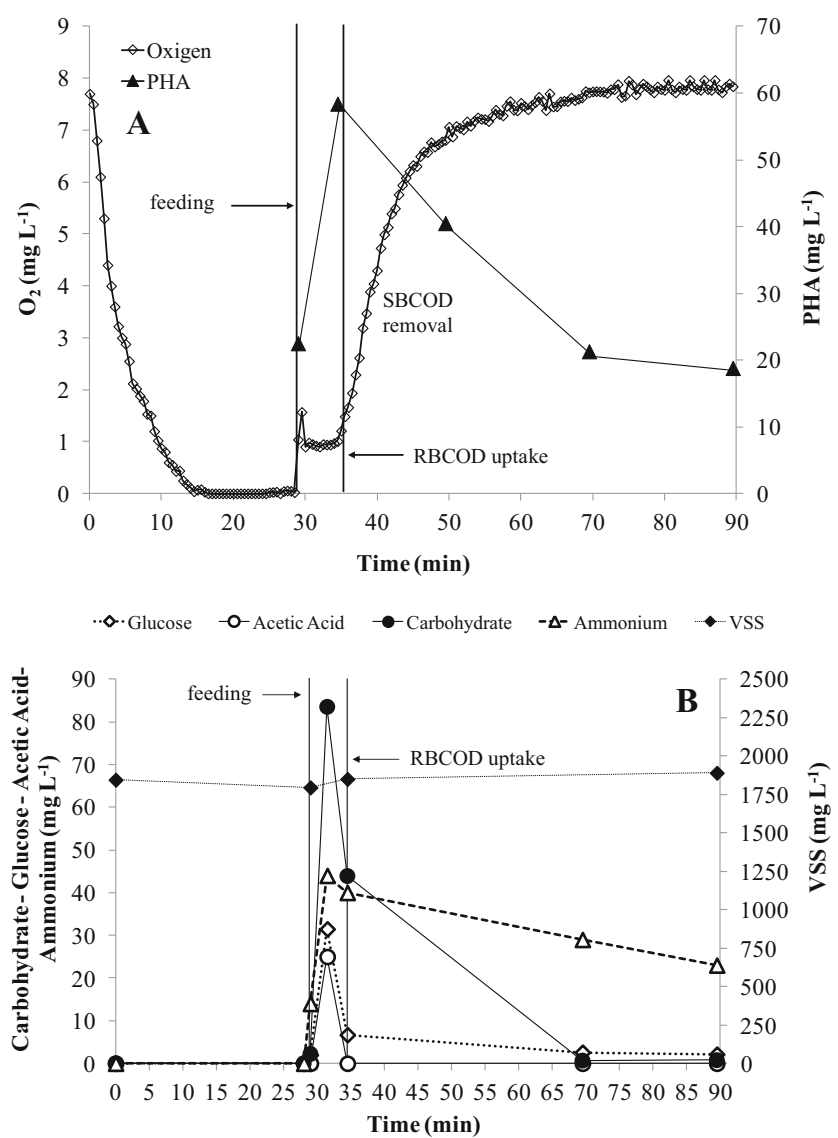

Fig. 2 Oxygen and PHA profiles (a) and VSS, ammonium, carbohydrates, glucose and acetic acid profiles (b) during the aerobic phases of a typical SBR cycle

phase (on average, $80-90 \%$ removal of influent COD at the end of the cycle).

Moreover, the oxygen inflection point where the depletion of RBCOD was assumed also corresponded to the maximum PHA concentration; on the other hand, the residual SBCOD did not seem to further contribute to the PHA storage (Fig. 2a). In principle, it cannot be excluded that during the famine phase, PHA storage and PHA degradation could have simultaneously occurred by different microorganisms; however, even under this assumption, the PHA consumption as the internal reserve by fast-storing microorganisms should have been faster than PHA formation on SBCOD, if any. The prevailing occurrence of growth during the famine phase was suggested by more evident ammonia consumption, even if some growth (as reflected by nitrogen removal) seems also to occur during the feast phase. Accordingly, the VSS concentration slightly increased during both the feast and famine phases, mostly due to the PHA storage during the feast phase and to the growth on both the SBCOD and the internal PHA reserve during the famine phase, respectively. Overall, the above reported time profiles suggest that a feast-famine regime was actually established in spite of only about half of the overall COD removal occurring during the feast phase.
Because operating conditions were always the same, a detailed analysis of the variability of process performance parameters was carried out in order to explain such a variability of storage performance among different runs.

\section{Selection of biomass on the substrate synthetic mixture: process reliability}

Among the six SBR runs, the average values of the feast phase length during the steady-state operation varied in the range 3.6-9.0 min, i.e. between 7 and $15 \%$ of the total length of the aerobic phase of the cycle (Table 1). Based on the wider experience gained on biomass selection by using acetate or VFA-rich streams (Albuquerque et al. 2007; Dionisi et al. 2006; Johnson et al. 2009; Jiang et al. 2011; Villano et al. 2010), short feast phase length, not higher than $20 \%$ of the aerobic cycle length, was necessary to ensure a strong selection in favour of MMC with high storage potential. Hence, in spite of the low VFA content of the substrate synthetic mixture (10.7\% of acetic acid COD basis), an appropriately short feast phase length was also obtained in the present research based on RBCOD, and this allowed to trigger the storage mechanism in all the SBR runs, with good reproducibility (Table 1). Nevertheless, the residual presence of SBCOD during the famine phase likely decreased the effectiveness of the feastfamine regime. This in turn negatively affected the stability of the biomass storage response, which was characterized by stronger fluctuations over time with respect to other parameters. As an example, Fig. 3 shows the time profiles of PHA production rate and substrate removal rate during the feast phase for the whole Run IV. The biomass was able to store PHA from the beginning of the operation, reaching the maximum peak of storage activity after 8.7 SRTs $(302 \mathrm{mg}$ $\mathrm{COD}_{\mathrm{PHA}} \mathrm{g} \mathrm{COD}_{\mathrm{Xa}}{ }^{-1} \mathrm{~h}^{-1}$ ); however, the PHA production rate remained quite variable. On the other hand, the specific RBCOD removal rate showed less fluctuations compared to the specific storage rate and even a slightly increasing trend until the end of the run, showing a progressive and slow acclimation to operating conditions.

In the same run, the capacity of the biomass to remove the total soluble COD was notably more stable. Starting from the $15^{\text {th }}$ day of operation, the COD removal efficiency changed in a tight range, between 74.8 and $93.4 \%$. This robust and stable COD removal efficiency allowed to obtain a clarified effluent with a soluble COD concentration often below $40 \mathrm{mg} \mathrm{L}^{-1}$ (Fig. 4).

Table 1 summarizes the results of the main parameters collected in the six SBR runs. The average RBCOD removal rate ranged among 255 (Run VI) and $569 \mathrm{mg}$ RBCOD g $\mathrm{COD}_{\mathrm{Xa}^{-1}} \mathrm{~h}^{-1}$ (Run III) whereas average PHA production rates (q $P^{\text {feast }}$ ) ranged between 54 (Run VI) and 136 mg COD PHA $\mathrm{g}$ $\mathrm{COD}_{\mathrm{Xa}^{-1}} \mathrm{~h}^{-1}$ (Run III). The average storage yield $\left(Y_{\mathrm{P} / \mathrm{S}}^{\text {feast }}\right)$ ranged among 0.18 (Run I-VI) and 0.26 (Run III) COD $_{\text {PHA }}$ 
Table 1 Main parameters with average values and standard deviations monitored in the six SBR runs

\begin{tabular}{|c|c|c|c|c|c|c|}
\hline Parameter & Run I & Run II & Run III & Run IV & Run V & Run VI \\
\hline Biomass at the end of feast (VSS, $\mathrm{mg} \mathrm{L}^{-1}$ ) & $2,514 \pm 92$ & $1,762 \pm 118$ & $1,444 \pm 77$ & $1,701 \pm 83$ & $2,175 \pm 51$ & $2,120 \pm 68$ \\
\hline PHA at the end of cycle (mg COD L $\left.{ }^{-1}\right)$ & $45 \pm 5$ & $30 \pm 4$ & $44 \pm 4$ & $41 \pm 4$ & $47 \pm 3$ & $35 \pm 2$ \\
\hline PHA at the end of feast (mg COD L ${ }^{-1}$ ) & $62 \pm 9$ & $47 \pm 7$ & $63 \pm 5$ & $57 \pm 5$ & $63 \pm 3$ & $52 \pm 3$ \\
\hline PHA content $\left(\%\right.$, g PHA g $\left.\mathrm{VSS}^{-1}\right)$ & $1.4 \pm 0.2$ & $1.5 \pm 0.2$ & $2.6 \pm 0.2$ & $2.1 \pm 0.2$ & $1.7 \pm 0.1$ & $1.2 \pm 0.2$ \\
\hline 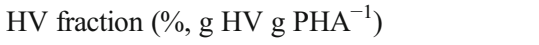 & $8 \pm 1$ & $9 \pm 2$ & $8 \pm 1$ & $5.9 \pm 0.5$ & $5.9 \pm 0.7$ & $4.2 \pm 0.4$ \\
\hline Feast phase length $(\%)$ & $6.7 \pm 0.3$ & $9.5 \pm 0.7$ & $8.0 \pm 0.6$ & $7.5 \pm 0.2$ & $12 \pm 1$ & $15 \pm 2$ \\
\hline$-\mathrm{q} S_{\mathrm{RBCOD}}\left(\mathrm{mg}\right.$ RBCOD g COD $\left.{ }_{\mathrm{Xa}}{ }^{-1} \mathrm{~h}^{-1}\right)$ & $446 \pm 23$ & $394 \pm 19$ & $569 \pm 36$ & $526 \pm 17$ & $272 \pm 15$ & $255 \pm 21$ \\
\hline $\mathrm{q} P^{\text {feast }}\left(\mathrm{mg} \mathrm{COD}_{\mathrm{PHA}} \mathrm{g} \mathrm{COD}_{\mathrm{Xa}}^{-1} \mathrm{~h}^{-1}\right)$ & $82 \pm 26$ & $79 \pm 20$ & $136 \pm 33$ & $113 \pm 13$ & $67 \pm 6$ & $54 \pm 4$ \\
\hline$Y_{\mathrm{P} / \mathrm{S}}^{\text {feast }}\left(\mathrm{COD}_{\mathrm{PHA}} \mathrm{RBCOD}^{-1}\right)$ & $0.18 \pm 0.06$ & $0.23 \pm 0.05$ & $0.26 \pm 0.04$ & $0.22 \pm 0.02$ & $0.24 \pm 0.02$ & $0.18 \pm 0.01$ \\
\hline$Y_{\mathrm{OBS}}^{\text {cycle }}\left(\mathrm{COD}_{\mathrm{VSS}} \mathrm{COD}^{-1}\right)$ & $0.56 \pm 0.02$ & $0.53 \pm 0.04$ & $0.52 \pm 0.02$ & $0.50 \pm 0.02$ & $0.49 \pm 0.02$ & $0.51 \pm 0.02$ \\
\hline Biomass in the effluent (VSS, $\mathrm{mg} \mathrm{L}^{-1}$ ) & $17 \pm 3$ & $41 \pm 4$ & $45 \pm 5$ & $38 \pm 3$ & $24 \pm 2$ & $15 \pm 3$ \\
\hline COD in the effluent $\left(\mathrm{mg} \mathrm{L}^{-1}\right)$ & $44 \pm 7$ & $43 \pm 6$ & $37 \pm 6$ & $33 \pm 2$ & $30 \pm 3$ & $30 \pm 6$ \\
\hline COD removal efficiency $(\%)$ & $80 \pm 6$ & $81 \pm 3$ & $84 \pm 5$ & $87 \pm 1$ & $89 \pm 5$ & $89 \pm 6$ \\
\hline Volumetric OLR (mg COD $\mathrm{CS}_{\mathrm{S}} \mathrm{L}^{-1}$ day $^{-1}$ ) & 3.08 & 3.08 & 3.08 & 3.08 & 3.08 & 3.08 \\
\hline SRT (day) & 2.46 & 1.70 & 1.50 & 1.72 & 2.24 & 2.54 \\
\hline Specific OLR (mg COD ${ }_{\Delta \mathrm{S}} \mathrm{mg} \mathrm{VSS}^{-1}$ day $^{-1}$ ) & 0.86 & 1.23 & 1.50 & 1.27 & 0.99 & 1.00 \\
\hline
\end{tabular}

$\mathrm{RBCOD}^{-1}$. Hence, it is evident that the best storage response was obtained during SBR Run III whereas poorest storage responses were obtained during Runs I and VI.

It was observed that, in spite settling properties of the sludge were good, average VSSs in the supernatant $\left(\mathrm{VSS}_{\mathrm{E}}\right)$
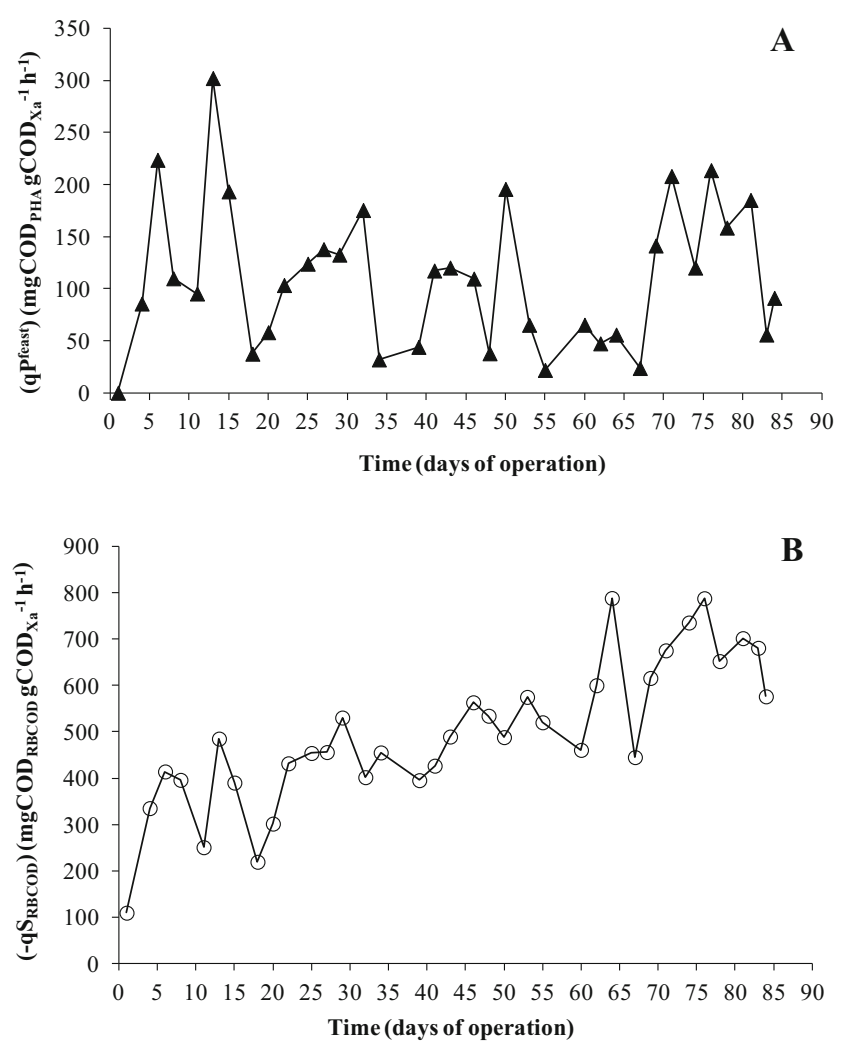

Fig. 3 Specific storage rate ( $\left.\mathrm{q} P^{\text {feast }}\right)$ and feast phase length (\%) (a) and RBCOD removal rate $\left(-\mathrm{q} S_{\mathrm{RBCOD}}\right)(\mathbf{b})$ profiles during SBR Run IV ranged among $15-45 \mathrm{mg} \mathrm{L}{ }^{-1}$. The $\mathrm{VSS}_{\mathrm{E}}$ variation among different SBR runs significantly affected the VSS level in the mixed liquor, and eventually, it also affected both SRT and sOLR. Figure 5a shows that the increase of the $\mathrm{VSS}_{\mathrm{E}}$ caused a decrease of both the VSS in the mixed liquor (from 3,579 to $2,060 \mathrm{mg} \mathrm{COD} \mathrm{L}^{-1}$ ) and the actual SRT (from 2.54 to 1.50 day). Because of the decrease of VSS with $\mathrm{VSS}_{\mathrm{E}}$ increase, the sOLR also increased from 0.86 to $1.27 \mathrm{mg} \mathrm{COD}_{\Delta \mathrm{S}}$ $\mathrm{mg} \mathrm{COD}_{\mathrm{Vss}}{ }^{-1}$ day $^{-1}$ (Fig. 5b).

Through the different sOLR and SRT values in the six SBR runs, the effect of changes of settling properties eventually caused a different storage response. Figure $6 \mathrm{a}, \mathrm{b}$ illustrates how observed storage performance was correlated to both SRT and sOLR. In fact, the increase of SRT from 1.50 to 2.54 days corresponded to a decrease of $\mathrm{q} P^{\text {feast }}$ from 136 (Run III) to 54 (Run VI) mg COD ${ }_{\mathrm{PHA}} \mathrm{g} \mathrm{COD}_{\mathrm{Xa}}{ }^{-1} \mathrm{~h}^{-1}$. The same behaviour was observed for the $Y_{\mathrm{P} / \mathrm{S}}{ }^{\text {feast }}$, which decreased as SRT increased.

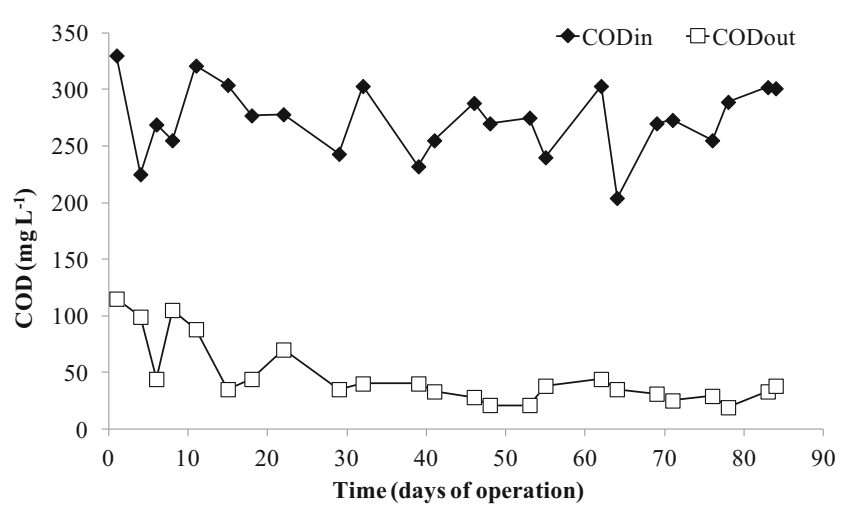

Fig. 4 Influent $\mathrm{COD}\left(\mathrm{COD}_{\text {in }}\right)$ and effluent $\mathrm{COD}\left(\mathrm{COD}_{\text {out }}\right)$ concentration trends during SBR Run IV 

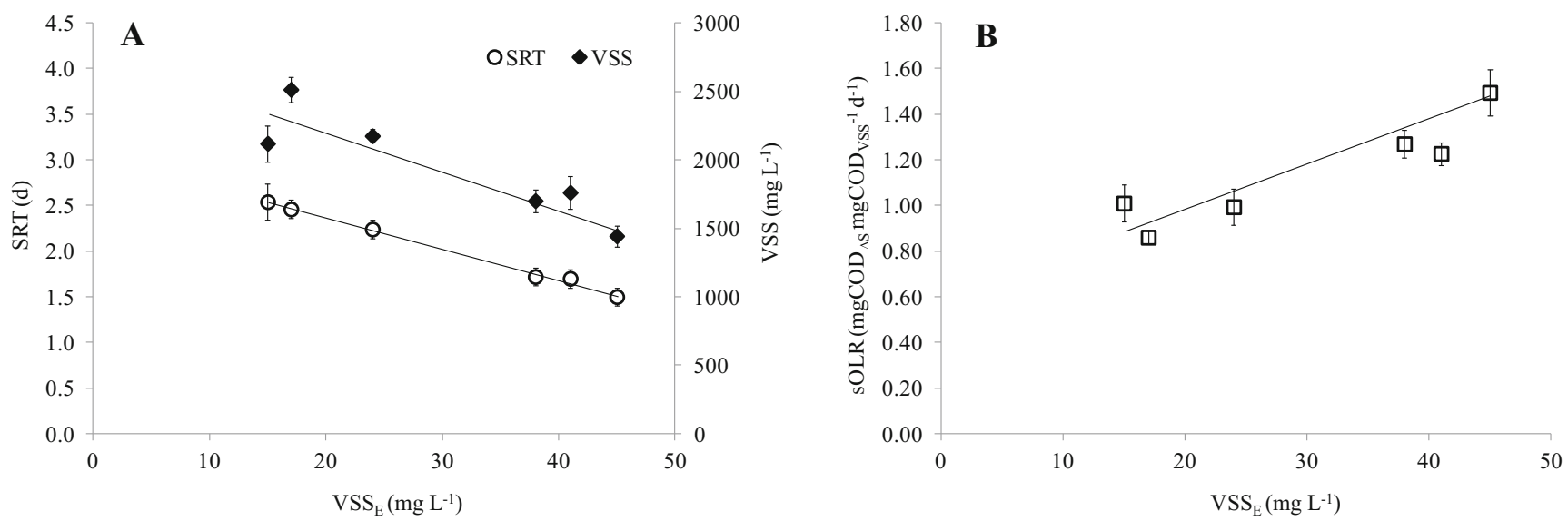

Fig. 5 Sludge retention time (SRT) and volatile suspended solids (VSS) in SBR (a) and specific organic load rate (sOLR) (b) as a function on VSS in the effluent $\left(\mathrm{VSS}_{\mathrm{E}}\right)$

\section{Microbial communities in SBR runs}

With the exception of Run VI, the microbial community dynamics was investigated during SBR operation via DGGE analysis, in order to assess the response to the imposed process conditions and the stability of PHA accumulating consortia during enrichment on the substrate synthetic mixture. Remarkable changes occurred in the structure of the community along all runs, being the Dice similarity indexes between the DGGE profiles at the beginning and the end of the SBR runs in the range 60 (Run I)-38\% (Run IV). In order to numerically measure community dynamics from the DGGE profiles, moving window analysis was performed (Fig. 7). It is shown that faster changes occurred during the first days of SBR operation (rate of change of $37.5 \pm 17.2,27.7 \pm 14.8$ and $11.5 \pm 3.5 \%$ for Runs I, II and III, respectively), when varying oxygen profiles also indicated that MMC acclimation was in progress. Conversely, very slow community changes occurred after the first week in all runs (rate of change between $3.1 \pm 0.5$ and $7.4 \pm 1.3 \%$ ), when more stable process performances (e.g. RBCOD specific removal rate) were established. Such a low level of community dynamics during the steady state of SBR runs indicates that different species might be able to slowly become dominant or exit the bacterial community over a long operation period, without interfering, however, with the overall functionality of the system. As an example, Fig. 8 shows the community DGGE profiles and clustering analysis of the longest SBR run (Run IV). Community profiles of the first 4 weeks of incubation clustered together (cluster I) and separately from those of weeks 6-12 (cluster II). In addition, subclustering of DGGE profiles from consecutive sampling points was observed (sub-clusters Ia, Ib, IIa, IIb), confirming that changes progressively occurred in the community structure. In particular, the phylotypes dominant during the first 4 weeks of steady state operation (bands $2,3,7,9$, sub-clusters Ia and Ib) became poorly represented at weeks 6-7 (subcluster IIa), when phylotypes represented by bands 1, 4, 6, 8 and 12 had the highest relative abundance, and partially recovered dominance (bands 3,7 ) during the last period of operation (weeks 10 and 12, sub-cluster IIb), when an additional new phylotype enriched (band 13). Major phylotypes enriched were identified in clonal libraries of Run IV community (sampling time 43 and 71 days) via DGGE screening and sequencing of clone inserts (Table 2). At least one phylotype
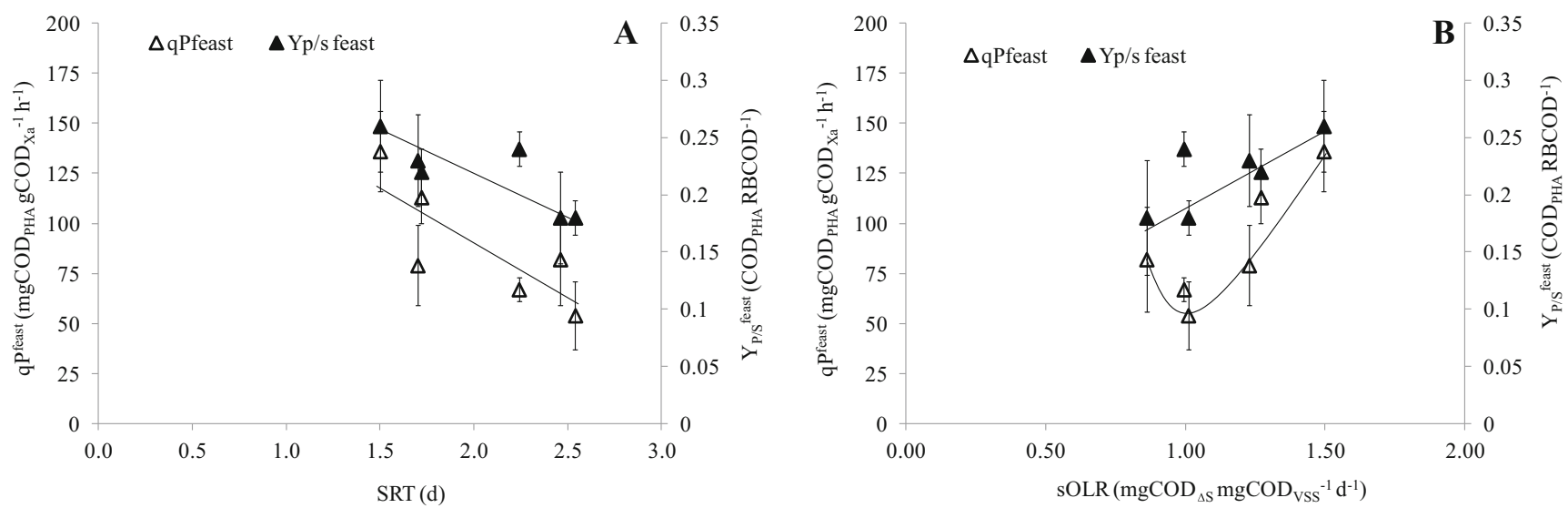

Fig. 6 Specific storage rate $\left(\mathrm{q} P^{\text {feast }}\right)$ and storage yield $\left(Y_{\mathrm{P} / \mathrm{S}}^{\text {feast }}\right)$ as a function of sludge retention time (SRT) (a) and of specific organic load rate (sOLR) (b) 


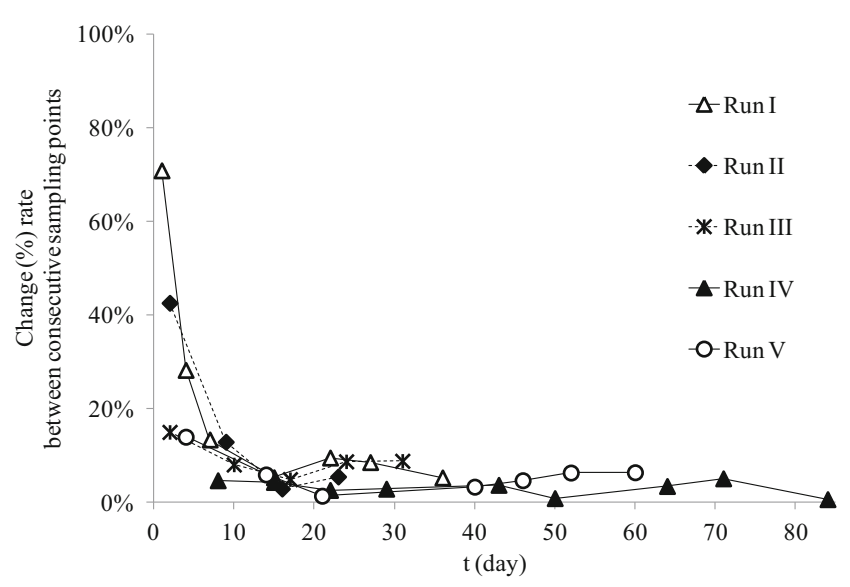

Fig. 7 Moving window analysis of the DGGE profiles of the microbial community enriched in different runs

among those dominant in each sub-cluster has been previously reported to store PHA, namely, Zoogloea sp. (band 9, dominant in sub-clusters Ia and Ib) (Huang et al. 2012), Acidovorax sp. (bands 3 and 7, dominant in sub-clusters Ia, Ib and IIb) (Yee et al. 2012), Hydrogenophaga sp. (bands 4 and 6, dominant in sub-clusters IIa) (Povolo et al. 2013; Choi et al. 2003) and Meganema perideroedes (band 13, dominant in sub-cluster IIb) (Kragelund et al. 2005), although it cannot be excluded that other main members of the community may have some PHA storage capability. Interestingly, some of these phylotypes were dominant in only one sub-cluster, indicating that a succession of different PHA producers occurred during the long operation period of the SBR. Since sharp fluctuations in the PHA production rate were observed throughout the whole run (Fig. 3), changes in the PHA storage rates were not dependent on changes in the microbial community and its dominant members (that occurred much more slowly).

A similar clustering behaviour was observed for the DGGE profiles of other runs (data not shown). The community enriched at the end of the short-lasting SBR Runs I, II and III (i.e. after 23-36 days) showed high similarity to the community enriched in Run IV after 15-29 days (clusters Ia and Ib) and was dominated by the same Zooglea sp. phylotype (band 9); similarly, the community enriched during the early phase of Run V (up to day 21) was dominated by the Zooglea phylotype along with one Acidovorax phylotype (band 3), while that enriched at the end of the run was more similar to
Fig. 8 DGGE profiles of the microbial community along Run IV (days indicated on top of lanes) and corresponding clustering dendrogram. Arrows and numbers indicate phylotypes (bands) that were identified in clone libraries via DGGE screening and sequenced

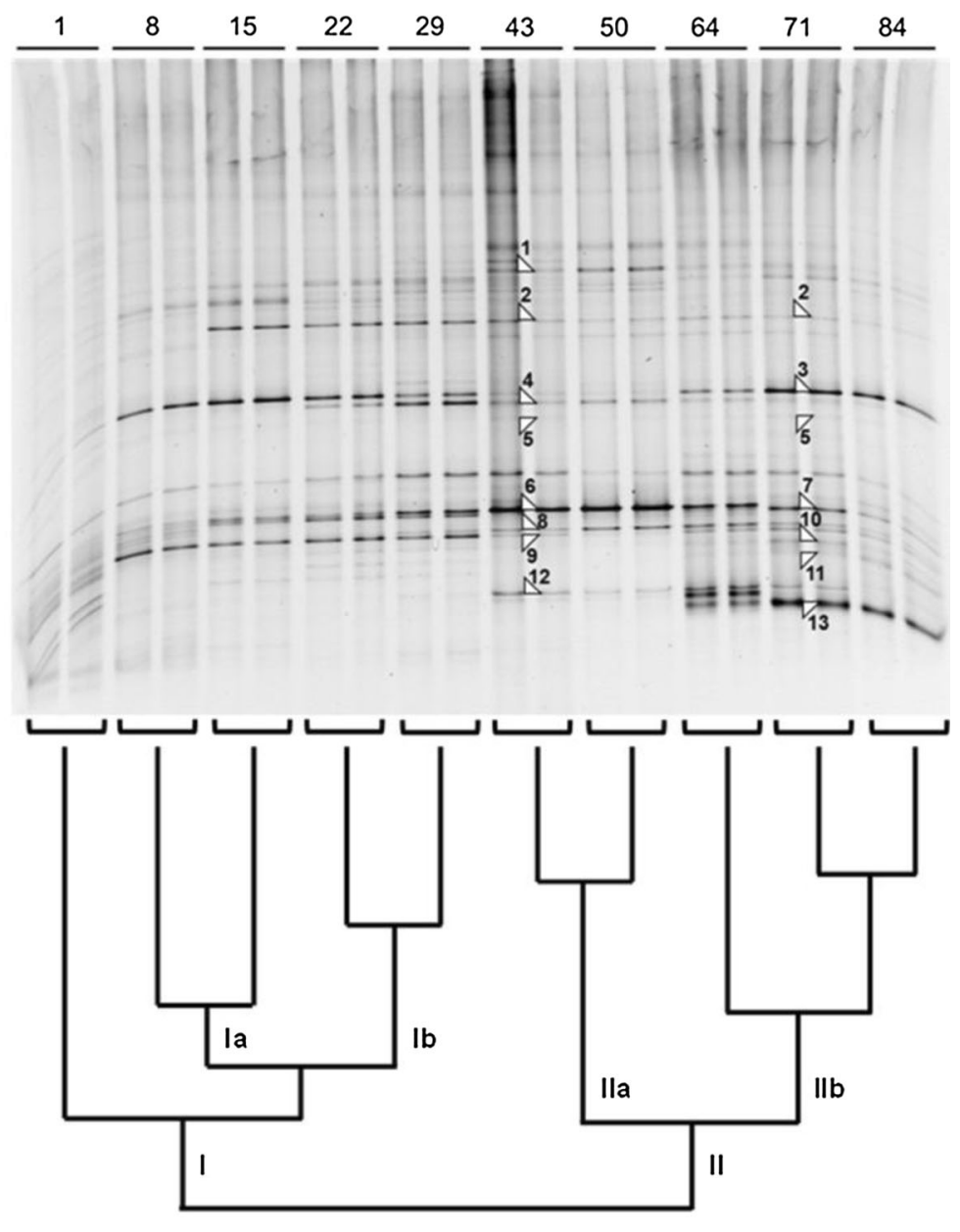




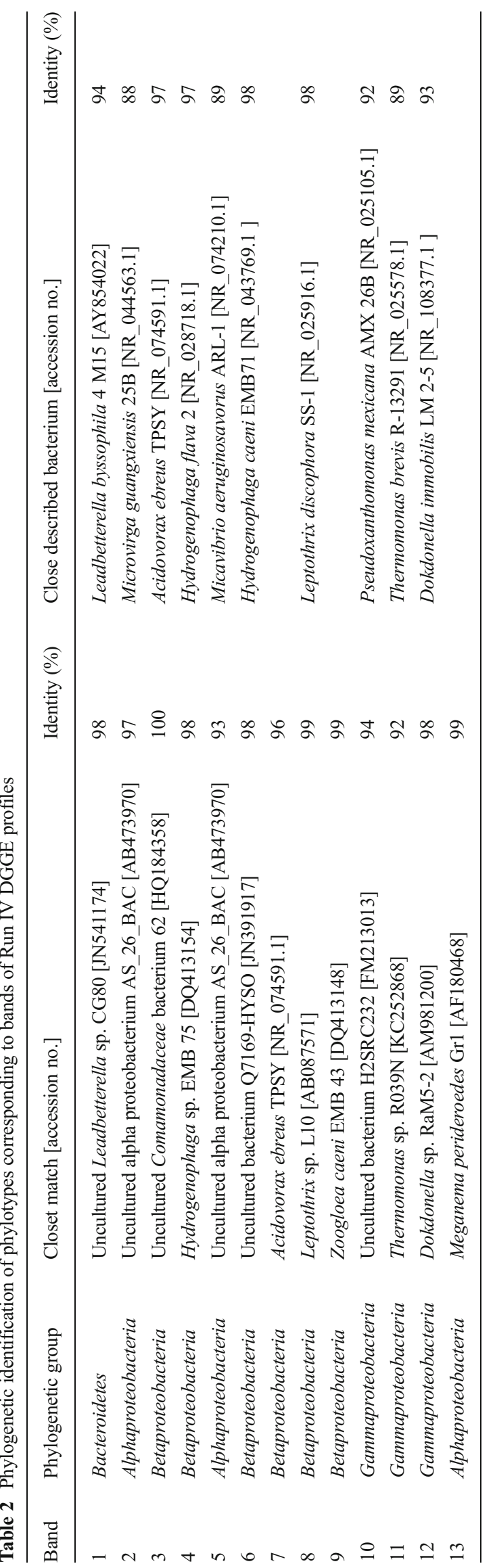

that enriched at the end of run IV and was dominated by the same Acidovorax phylotypes (bands 3 and 7) (data not shown). Although some differences were detected in the communities enriched (e.g. the absence of the M. perideroedes phylotyope at the end of Run V), this indicates that similar trends of succession of PHA-storing populations occurred over time in the different runs.

Third stage performance

\section{Short-term accumulation batch tests}

With the exception of Run I, short-term batch tests were carried out by using the acclimated biomass coming from steady-state SBR runs. These tests were performed in order to explore the storage potential of the selected MMCs when shifting to a concentrated VFA-rich stream (acetic and propionic acid) to which they had not previously been acclimated. As shown Fig. 9a, b, the typical response of the biomass to the initial VFA spike was described by the sudden increase of the OUR, which maintained a slightly increasing trend until the end of the test. This increase was likely due to the simultaneous biomass growth, as suggested by the ammonium uptake. The acetic and propionic acid were simultaneously removed with a total specific rate $\left(-\mathrm{q} S_{\mathrm{VFA}}{ }^{\text {batch }}\right)$ of $163 \mathrm{mg} \mathrm{COD}$ VFA $\mathrm{g} \mathrm{COD}_{\mathrm{Xa}}{ }^{-1} \mathrm{~h}^{-1}$ (on average).

Even if the biomass did not show any apparent lag phase due to the substrate change between the SBR and the accumulation stage, a physiological adaptation period can be anyway assumed by comparing the "- $-\mathrm{q} S_{\mathrm{VFA}}$ batch" during the accumulation with the "- $q S_{\text {RBCOD" }}$ " in the SBR feast phase.

Indeed, in all SBR run, the enriched biomass exhibited a decrease of the substrate uptake rate when exposed to the substrate shift: the $-\mathrm{q} S_{\mathrm{VFA}}{ }^{\text {batch }}$ being lower than the corresponding- $\mathrm{q} S_{\mathrm{RBCOD}}$ values, with closer values only in Run $\mathrm{V}$ (198 mg COD $\mathrm{VFA}_{\mathrm{VA}} \mathrm{gOD}_{\mathrm{Xa}^{-1}} \mathrm{~h}^{-1}$ in the batch test vs $272 \mathrm{mg}$ RBCOD g COD ${ }_{\mathrm{Xa}}{ }^{-1} \mathrm{~h}^{-1}$ in the SBR).

Accordingly, the PHA production rate in batch (q $\left.P^{\text {batch }}\right)$ was also lower than in SBR ( $\left(P^{\text {feast }}\right)$, with the exception of Runs $\mathrm{V}$ and VI, being the respective values 63 vs $67 \mathrm{mg} \mathrm{COD}_{\mathrm{PHA}} \mathrm{g}$ $\mathrm{COD}_{\mathrm{Xa}}{ }^{-1} \mathrm{~h}^{-1}$ in Run $\mathrm{V}$ and 48 vs $54 \mathrm{mg} \mathrm{COD}_{\mathrm{PHA}} \mathrm{g}$ $\mathrm{COD}_{\mathrm{Xa}}{ }^{-1} \mathrm{~h}^{-1}$ in Run VI.

As consequence of the observed lower accumulation kinetics, the 6-h accumulation did not allow to reach the polymer saturation of the biomass. In fact, the PHA production proceeded almost linearly until the end of the test, and it is easy to suppose that the biomass was still able to accumulate PHA inside the cells, also due to the relatively low PHA content achieved after $6 \mathrm{~h}$ of accumulation (10.3-13.9 g PHA g VSS ${ }^{-1}$, Table 3 ).

The composition of the stored copolymer, P[3-HB-co-3$\mathrm{HV}]$, reflected the specific rates on the single monomer production. As an example, the biomass enriched in Runs IV and V 

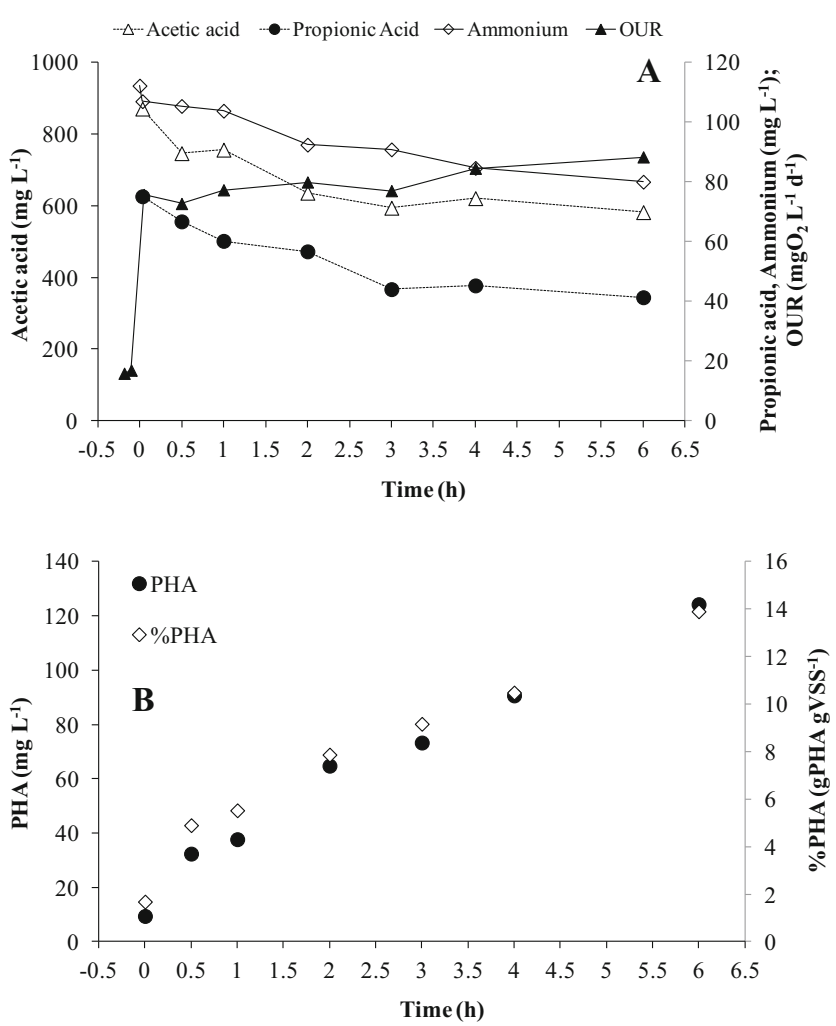

Fig. 9 Acetic and propionic acid, ammonium and OUR profiles (a). PHA concentration and biomass PHA content profiles (b) during a short-term batch test under nitrogen excess with biomass acclimated in SBR Run III

exhibited a kinetics for the HV monomer storage higher than the $\mathrm{HB}$ monomer, the ratio $\mathrm{qHV}^{\text {batch }} / \mathrm{qHB}^{\text {batch }}$ being 1.50 and 1.13 , respectively. This caused a very high $\mathrm{HV}$ content equal to 46 and $42 \% \mathrm{~g} \mathrm{HV} \mathrm{g} \mathrm{PHA}{ }^{-1}$. More in general, the HV fraction was generally high in all runs, with the exception for the biomass acclimated in Run III, which was characterized by an HV

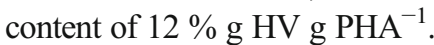

As already observed, both the SRT and sOLR established during MMC selection in the SBR also affected its storage response during the accumulation test. In fact the $Y_{\mathrm{P} / \mathrm{S}}^{\text {batch }}$ at $6 \mathrm{~h}$ decreased from 0.23 to $0.15 \mathrm{COD}_{\mathrm{PHA}} \mathrm{COD}_{\Delta \mathrm{s}^{-1}}$ using biomass that had been acclimated in the SBR at SRT increasing from 1.5 to 2.54 days. The same trend was observed for the PHA biomass content at $6 \mathrm{~h}$ of accumulation (Fig. 10a). This was consistent with the negative effect of the SRT increase on the selection of PHA-storing MMC. Similarly, due to the positive effect of the applied sOLR on the selection of storing biomass in SBR, an increasing storage response during accumulation was observed when the selected biomass was taken from SBR runs at increasing sOLR. In fact, both $Y_{\mathrm{P} / \mathrm{S}}{ }^{\text {batch }}$ and PHA content measured at $6 \mathrm{~h}$ of accumulation increased respectively from 0.15 to $0.23 \mathrm{COD}_{\mathrm{PHA}} \mathrm{COD}_{\Delta \mathrm{S}}{ }^{-1}$ and from 10.3 to $13.9 \mathrm{~g} \mathrm{PHA} \mathrm{g} \mathrm{VSS}^{-1}$, as sOLR in the SBR had increased from 1.00 to $1.50 \mathrm{mg} \mathrm{COD} \mathrm{CS}_{\Delta \mathrm{s}} \mathrm{mg}$ $\mathrm{VSS}^{-1}$ day $^{-1}$ (Fig. 10b).

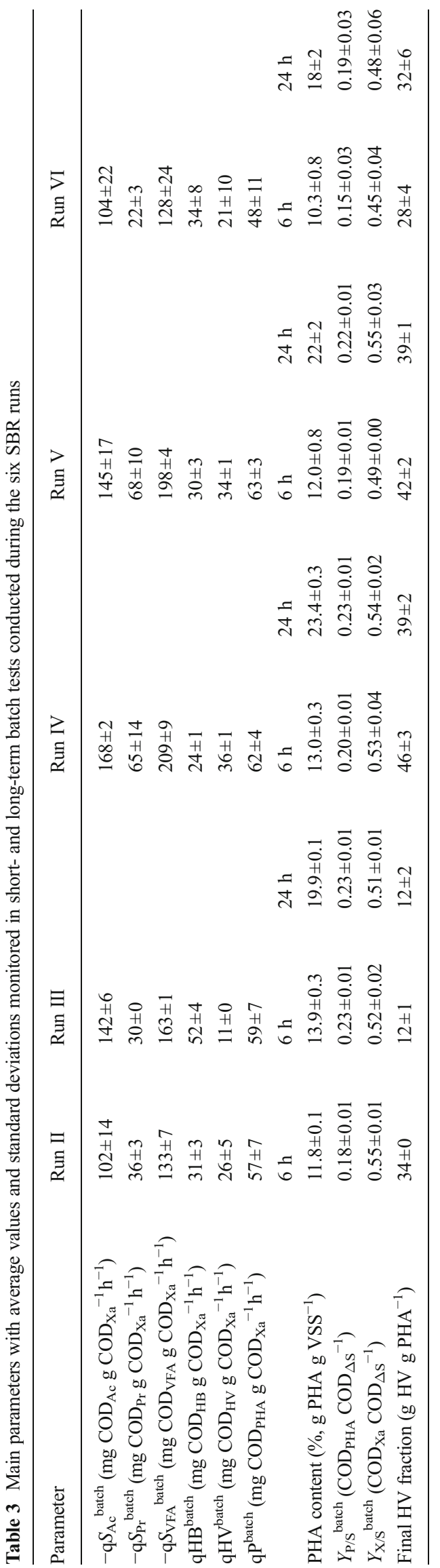




\section{Long-term accumulation batch tests}

Because PHA saturation of the biomass was not reached in short-term $(6 \mathrm{~h})$ batch tests, some of the tests were also conducted overnight to extend the time of the accumulation up to $24 \mathrm{~h}$ (after a second substrate spike in order to maintain a high VFA concentration).

The biomass was able to continuously store the PHA until the end of the test; surprisingly, a slight increase of the final $Y_{\mathrm{P} / \mathrm{S}}{ }^{\text {batch }}$ was also observed (from 0.20 to $0.23 \mathrm{COD}_{\mathrm{PHA}}$ $\mathrm{COD}_{\Delta \mathrm{S}}{ }^{-1}$ in Run IV, from 0.19 to $0.22 \mathrm{COD}_{\mathrm{PHA}} \mathrm{COD}_{\Delta \mathrm{S}}{ }^{-1}$ in Run V and from 0.15 to $0.19 \mathrm{COD}_{\mathrm{PHA}} \mathrm{COD}_{\Delta \mathrm{S}}{ }^{-1}$ in Run VI; Table 3). The increase of the final biomass PHA content was also significant, e.g. from 13.9 to $19.9 \%$ in Run III, from 13.0 to $23.4 \%$ in Run IV, from 12.0 to $22 \% \mathrm{~g} \mathrm{PHA} \mathrm{g} \mathrm{VSS}^{-1}$ in Run V and from 10.3 to $18 \% \mathrm{~g}$ PHA $\mathrm{g} \mathrm{VSS}^{-1}$ in Run VI.

The accumulation performance of the MMC biomass enriched herein is certainly lower than that typically reported when using MMCs selected on VFA-rich concentrated streams (Reis et al. 2011). Therefore, optimization of both selection and accumulation steps is still required.

\section{Conclusions}

Dynamic feeding using a VFA-poor, low-strength substrate synthetic mixture allowed to establish a stable feast-famine regime $(6.7-15 \%$ of the aerobic phase of the cycle), based on the feed RBCOD, which in turn ensured the selection/ enrichment of MMCs with PHA storage properties. Indeed, during the feast phase, the selected MMCs were characterized by specific storage rate in the range 54-136 $\mathrm{mg} \mathrm{COD}_{\mathrm{PHA}} \mathrm{g}$ $\mathrm{COD}_{\mathrm{Xa}}{ }^{-1} \mathrm{~h}^{-1}$ and a storage yield in the range $0.18-0.26 \mathrm{~g}$ $\mathrm{COD}_{\mathrm{PHA}} \mathrm{RBCOD}^{-1}$. Additionally, the prevailing microorganisms were identified as already known PHA-storing microorganisms: Zooglea sp., Acidovorax sp., Hydrogenophaga sp. and $M$. perideroedes.

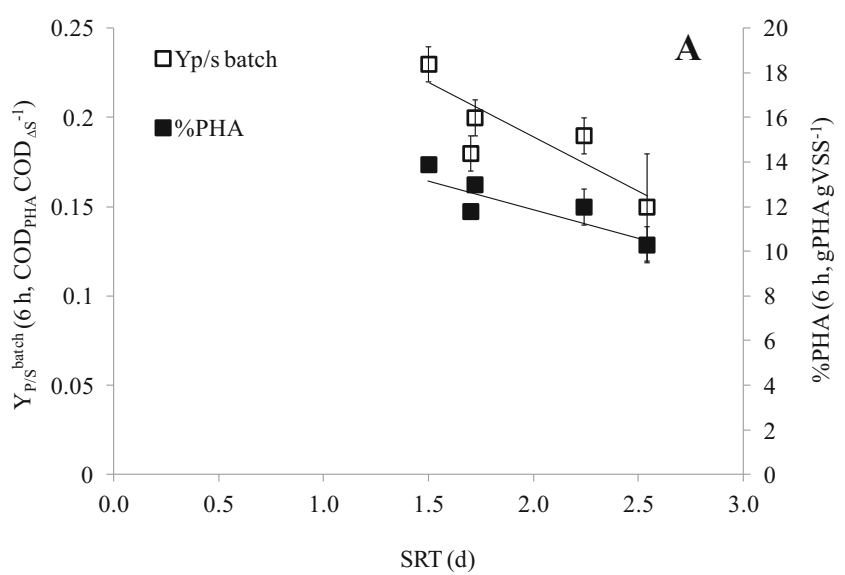

Based on most relevant process parameters, such as oxygen profiles and substrate removal efficiency, the SBR runs showed a very good reproducibility. On the other hand, the storage response showed a stronger and quicker variability than other process parameters. Furthermore, this variability seemed not to be strongly linked to the microbial community evolution, which was much slower along time than the observed storage response changes. Therefore, one may consider that the biomass physiological state may vary and thereby influence the PHA accumulation response.

Based on the averaged data from the different SBR runs, the storage response was directly linked to the SRT and sOLRs, influenced by the biomass settling properties and effluent VSS. This was further evidenced by the storage activity exhibited in the following batch accumulation tests, especially during the first $6 \mathrm{~h}$. This "uncontrolled" variation of SRT and sOLR appears as the principal factor affecting the storage properties of MMC in spite of no significant effect was exerted on the main known PHA-storing microbes enriched. However, the communities enriched in all runs were not identical. Changes in some minor members (either PHA storing or not) might have slightly influenced the settling properties of the sludge and thus the STR. Since the same operating conditions were used, these changes might be due to the different inocula used. Hence, in order to optimize the process, any effort should be made to maintain the SRT and SOLR as at optimally as possible.

From a practical point of view, the MMC was able to accumulate polymer up to $23 \% \mathrm{~g}^{\mathrm{PHA} \mathrm{g} \mathrm{VSS}}{ }^{-1}$ after $24 \mathrm{~h}$ of accumulation that was still far from saturation value. Further work is needed for improving the storage response of the biomass. On the other hand, the process remains quite appealing for the possibility to use a low-strength MWW for directly producing the biomass in the selection step, so saving for the accumulation step all the available VFAs coming from acidogenic fermentation. Moreover, the integration of the

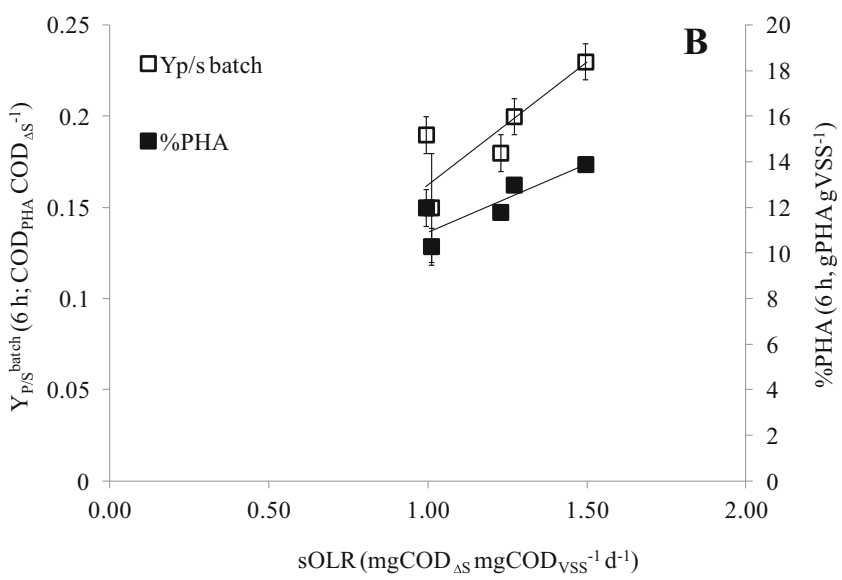

Fig. 10 Storage yield $\left(Y_{\mathrm{P} / \mathrm{S}}{ }^{\text {batch }}\right)$ and PHA content in the biomass (\%) at $6 \mathrm{~h}$ in accumulation tests (nitrogen excess) as a function of sludge retention time (SRT) (a) and specific organic load rate (sOLR) (b) in SBR 
selection step in a wastewater treatment line is intriguing because both the primary and secondary sludge is diverted to the PHA production process.

The feasibility of using VFA-rich waste streams for PHA accumulation, differing from that used for biomass selection, was demonstrated also at pilot scale, and further optimization is being carried out. Higher PHA content of $34 \% \mathrm{~g}$ PHA g $\mathrm{VSS}^{-1}$ has been achieved after 20 -h fed-batch accumulation using acetate (provided with feed on demand strategy) and biomass selected with VFA-poor real municipal wastewater (Morgan-Sagastume et al. 2014).

Acknowledgments This work was supported by the EU ROUTES project (Contract No 265156, FP7 2007-2013, THEME [ENV.2010.3.1.1-2] Innovative system solutions for municipal sludge treatment and management).

\section{References}

Albuquerque MGE, Eiroa M, Torres C, Nunes BR, Reis MAM (2007) Strategies for the development of a side stream process for polyhydroxyalkanoate (PHA) production from sugar cane molasses. J Biotechnol 130:411-421

Albuquerque MGE, Torres CAV, Reis MAM (2010) Polyhydroxyalkanoates (PHA) production by a mixed microbial culture using sugar molasses: effect of the influent substrate concentration on culture selection. Water Res 44:3419-3433

Andalib M, Nakhla G, Zhu J (2010) Dynamic testing of the twin circulating fluidized bed bioreactor (TCFBBR) for nutrient removal from municipal wastewater. Chem Eng J 162:616-625

Anterrieu S, Quadri L, Geurkink B, Dinkla I, Bengtsson S, ArcosHernandez M, Alexandersson T, Morgan-Sagastume F, Karlsson A, Hjort M, Karabegovic L, Magnusson P, Johansson P, Christensson M, Werker A (2013) Integration of biopolymer production with process water treatment at a sugar factory. New Biotechol 31:308-323

Antoniadis A, Takavakoglou V, Zalidis G, Darakas E, Poulios I (2010) Municipal wastewater treatment by sequential combination of photocatalytic oxidation with constructed wetlands. Catal Today 151: $114-118$

Beccari M, Bertin L, Dionisi D, Fava F, Lampis S, Majone M, Valentino F, Vallini G, Villano M (2009) Exploiting olive oil mill effluents as a renewable resource for production of biodegradable polymers through a combined anaerobic-aerobic process. J Chem Technol Biotechnol 84:901-908

Bengtsson S, Werker A, Christensson M, Welander T (2008) Production of polyhydroxyalkanoates by activated sludge treating a paper mill wastewater. Bioresour Technol 99:509-516

Braunegg G, Sonnleitner B, Lafferty RMA (1978) Rapid gas chromatographic method for the determination of poly- $\beta$-hydroxybutyric acid in microbial biomass. Eur J Appl Microbiol 6:29-37

Carucci A, Dionisi D, Majone M, Rolle E, Smurra P (2001) Aerobic storage by activated sludge on real wastewaters. Water Res 35: 3833-3844

Chanprateep S (2010) Current trends in biodegradable polyhydroxyalkanoates. J Biosci Bioeng 110:621-632

Chen Z, Wen Q, Wang J, Li F (2006) Simultaneous removal of carbon and nitrogen from municipal-type synthetic wastewater using netlike rotating biological contactor (NRBC). Process Biochem 41: 2468-2472
Choi MH, Lee HJ, Rho JK, Yoon SC, Nam JD, Lim D, Lenz RW (2003) Biosynthesis and local sequence specific degradation of poly(3hydroxyvalerate-co-4-hydroxybutyrate) in Hydrogenophaga pseudoflava. Biomacromolecules 4:38-45

Chua ASM, Takabatake H, Satoh H, Mino T (2003) Production of polyhydroxyalkanoates (PHA) by activated sludge treating municipal wastewater: effect of $\mathrm{pH}$, sludge retention time (SRT), and acetate concentration in influent. Water Res 37:3602-3611

Dias JML, Lemos PC, Serafim LS, Oliveira C, Eiroa M, Albuquerque MGE, Ramos AM, Oliveira R, Reis MAM (2006) Recent advanced in polyhydroxyalkanoates production by mixed aerobic cultures: from the substrate to the final product. Macromol Biosci 6:885-906

Dionisi D, Majone M, Tandoi V, Beccari M (2001) Sequencing batch reactor: influence of periodic operation on performance of activated sludges in biological wastewater treatment. Ind Eng Chem Res 40: $5110-5119$

Dionisi D, Majone M, Vallini G, Di Gregorio S, Beccari M (2006) Effect of the applied organic load rate on biodegradable polymer production by mixed microbial cultures in a sequencing batch reactor. Biotechnol Bioeng 93:76-88

Gujer W, Henze M (1991) Activated sludge modeling and simulation. Water Sci Technol 23:1011-1023

Huang YT, Chen PL, Semblante GU, You SJ (2012) Detection of polyhydroxyalkanoate-accumulating bacteria from domestic wastewater treatment plant using highly sensitive PCR primers. J Microbiol Biotechnol 22:1141-1147

Jia Q, Wang H, Wang X (2013) Dynamic synthesis of polyhydroxyalkanoates by bacterial consortium from simulated excess sludge fermentation liquid. Bioresour Technol 140:328-336

Jiang Y, Marang L, Kleerebezem R, Muyzer G, van Loosdrecht MCM (2011) Effect of temperature and cycle length on microbial competition in PHB-producing sequencing batch reactor. ISME J 5:896907

Jin Y, Ding D, Feng C, Tong S, Suemura T, Zhang F (2012) Performance of sequencing batch biofilm reactors with different control systems in treating synthetic municipal wastewater. Bioresour Technol 104: $12-18$

Johnson K, Jiang Y, Kleerebezem R, Muyzer G, van Loosdrecht MCM (2009) Enrichment of a mixed bacterial culture with a high polyhydroxyalkanoate storage capacity. Biomacromolecules 10 : 670-676

Kargi F, Uygur A (2003) Nutrient removal performance of a five-step sequencing batch reactor as a function of wastewater composition. Process Biochem 38:1039-1045

Kositzi M, Poulios I, Malato S, Caceres J, Campos A (2004) Solar photocatalytic treatment of synthetic municipal wastewater. Water Res 38:1147-1154

Kragelund C, Nielsen JL, Thomsen TR, Nielsen PH (2005) Ecophysiology of the filamentous Alphaproteobacterium Meganema perideroedes in activated sludge. FEMS Microbiol Ecol 54:111-122

Liu HY, Hall PV, Darby JL, Coats ER, Green PG, Thompson DE, Loge FJ (2008) Production of polyhydroxyalkanoates during treatment of tomato cannery wastewater. Water Environ Res 80: $367-372$

Majone M, Massanisso P, Carucci A, Lindrea K, Tandoi V (1996) Influence of storage on kinetic selection to control aerobic filamentous bulking. Water Sci Technol 34:223-232

Marzorati M, Wittebolle L, Boon N, Daffonchio D, Verstraete W (2008) How to get more out of molecular fingerprints: practical tools for microbial ecology. Environ Microbiol 10:1571-1581

Morgan-Sagastume F, Karlsson A, Johansson P, Pratt S, Boon N, Lant P, Werker A (2010) Production of polyhydroxyalkanoates in open mixed cultures from a waste sludge stream containing high levels of soluble organics, nitrogen and phosphorous. Water Res 44:51965211 
Morgan-Sagastume F, Valentino F, Hjort M, Cirne D, Karabegovic L, Gerardin F, Johansson P, Karlsson A, Magnusson P, Alexandersson T, Bengtsson S, Majone M, Werker A (2014) Polyhydroxyalkanoate (PHA) production from sludge and municipal wastewater treatment. Water Sci Technol 69:177-184

Povolo S, Romanelli MG, Basaglia M, Ilieva VI, Corti A, Morelli A, Chiellini E, Casella S (2013) Polyhydroxyalkanoate biosynthesis by Hydrogenophaga pseudoflava DSM1034 from structurally unrelated carbon sources. New Biotechnol 30: 629-634

Pozo G, Villamar AC, Martinez M, Vidal G (2011) Polyhydroxyalkanoates (PHA) biosynthesis from kraft mill wastewater: biomass origin and C: N relationship influence. Water Sci Technol 63:449-455

Reddy Venkateswar M, Mohan Venkata S (2012) Effect of substrate load and nutrients concentration on the polyhydroxyalkanoates (PHA) production using mixed consortia through wastewater treatment. Bioresour Technol 114:573-582

Reis MAM, Albuquerque MGE, Villano M, Majone M (2011) Mixed culture processes for polyhydroxyalkanoate production from agroindustrial surplus/wastes as feedstocks. Compr Biotechnol 6:669683

Sambrook J, Fritsch ER, Maniatis T (1989) Molecular cloning: a laboratory manual. Cold Spring Harbor Laboratory Press, Cold Spring Harbor (NY), 2

Serafim LS, Lemos PC, Oliveira R, Reis MAM (2004) Optimization of polyhydroxyalkanoates production by mixed cultures submitted to aerobic dynamic feeding conditions. Biotechnol Bioeng 87:145-160
Valentino F, Beccari M, Fraraccio S, Zanaroli G, Majone M (2013) Feed frequency in a Sequencing Batch Reactor strongly affects the production of polyhydroxyalkanoates (PHAs) from volatile fatty acids. New Biotechnol 31:264-275

Villano M, Lampis S, Valentino F, Vallini G, Majone M, Beccari M (2010) Effect of hydraulic and organic loads in a sequencing batch reactor on microbial ecology of activate sludge and storage of polyhydroxyalkanoates. Chem Eng Trans 20:187-192

Wang F, Lee SY (1997) Production of poly(3-hydroxybutyrate) by fedbatch culture of filamentation-suppressed recombinant Escherichia coli. Appl Environ Microbiol 63:4765-4769

Wu H, Yang D, Zhou Q, Song Z (2009) The effect of $\mathrm{pH}$ on anaerobic fermentation of primary sludge at room temperature. J Hazard Mater 172:196-201

Yee LN, Chuah JA, Chong ML, Phang LY, Raha AR, Sudesh K, Hassan MA (2012) Molecular characterisation of phaCAB from Comamonas sp. EB172 for functional expression in Escherichia coli JM109. Microbiol Res 167:550-557

Yoo R, Kim J, McCarty PL, Bae J (2012) Anaerobic treatment of municipal wastewater with a staged anaerobic fluidized membrane bioreactor (SAF-MBR) system. Bioresour Technol 120:133-139

Yuan Q, Baranowski M, Oleszkiewicz JA (2010) Effect of sludge type on the fermentation products. Chemosphere 80:445-449

Zanaroli G, Di Toro S, Todaro D, Varese GC, Bertolotto A, Fava F (2010) Characterization of two diesel fuel degrading microbial consortia enriched from a non acclimated, complex source of microorganisms. Microb Cell Factories 9:10 